\title{
Copper contamination of self-assembled organic monolayer modified silicon surfaces following a 'click' reaction characterized with LAPS and SPIM
}

\author{
Fan $\mathrm{Wu}^{1}$, De-Wen Zhang ${ }^{1,3}$, Jian Wang ${ }^{1,4}$, Michael Watkinson ${ }^{2}$, Steffi Krause ${ }^{1 *}$ \\ ${ }^{1}$ School of Engineering and Materials Science, Queen Mary University of London, Mile End \\ Road, London E1 4NS, UK \\ ${ }^{2}$ School of Biological and Chemical Sciences, Queen Mary University of London, Mile End \\ Road, London E1 4NS, UK \\ ${ }^{3}$ Institute of Materials, China Academy of Engineering Physics, Jiangyou, 621908, Sichuan, \\ P.R. China \\ ${ }^{4}$ Institute of Medical Engineering, School of Basic Medical Science, Xi'an Jiaotong \\ University Health Science Center, Xi'an 710061, P.R. China \\ *Corresponding author: s.krause@qmul.ac.uk, Telephone +44 (0)2078823747
}

\begin{abstract}
A copper(I) catalyzed azide alkyne cycloaddition (CuAAC) reaction, combined with microcontact printing was employed successfully to pattern alkyne terminated self-assembled organic monolayer modified silicon surfaces. Despite the absence of a copper peak in X-ray photoelectron spectra (XPS), copper contamination was found and visualized using lightaddressable potentiometric sensors (LAPS) and scanning photo-induced impedance microscopy (SPIM) after the 'click' modified silicon surfaces were rinsed with hydrochloric acid $(\mathrm{HCl})$ solution, which has been frequently used to remove copper residues in the past. Even cleaning with an ethylenediaminetetraacetic acid (EDTA) solution did not remove the copper residue completely. Different strategies for avoiding copper contamination, including the use of bulky chelators for the copper(I) catalyst and rinsing with different reagents, were
\end{abstract}


tested. Only cleaning of the silicon surfaces with an EDTA solution containing trifluoroacetic acid (TFA) after the 'click' modification proved to be an effective method as confirmed by LAPS and SPIM results, which showed the expected potential shift due to the surface charge introduced by functional groups in the monolayer and allowed, for the first time, to image the impedance of an organic monolayer.

\section{Introduction}

'Click' chemistry, especially the $\mathrm{Cu}(\mathrm{I})$-catalysed azide alkyne cycloaddition (CuAAC) reaction, has been used extensively to modify silicon surfaces ${ }^{1,2,3,4,5,6}$, due to its many advantages, such as high selectivity and yield, mild reaction conditions and good compatibility with various solvents, since it was first described by Sharpless in $2001^{7}$. However, few investigations have been made on the copper residue that remains on silicon surfaces after 'click' reactions despite its potentially detrimental effect on biological systems and contamination issues in other applications ${ }^{8,9}$. X-ray photoelectron spectroscopy (XPS) is one of the most widely used methods to characterize copper ions on silicon surfaces. Gooding's group showed that a $\mathrm{Cu} 2 \mathrm{p} 3 / 2$ emission at $\sim 933 \mathrm{eV}$ was present in the XPS spectra when there was a trace of residual copper following a 'click' reaction on alkyneterminated silicon surfaces ${ }^{10}$. However, following rinsing of the modified samples with dilute

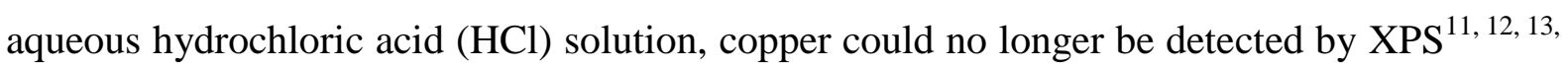
14,15

Patterning silicon surfaces is a fundamental method to maintain a high signal-to-noise ratio for many biosensors where the patterned areas act as sensing elements that interact directly with analytes such as biomolecules, viruses, bacteria or cells, while the background of the substrate stays inactive to analyte deposition. The two most widely used methods for chemically patterning silicon surfaces modified with self-assembled organic monolayers are 
photolithography ${ }^{12,13,16}$ and microcontact printing $(\mu \mathrm{CP})^{17,18,19,20,21,22}$. We have recently reported that photolithography not only introduces chemically bonded contaminants, but also decreases the coverage of the monolayers on silicon ${ }^{23}$. Meanwhile, we have also demonstrated that the strategy of combining $\mu \mathrm{CP}$ with 'click' chemistry on alkyne terminated surfaces is non-destructive and efficient.

Light-addressable potentiometric sensors (LAPS) and scanning photo-induced impedance microscopy (SPIM), both of which are based on photocurrent measurements at electrolyte /insulator /semiconductor (EIS) field-effect structures can be used to detect local surface electrical potentials ${ }^{24}$ and impedance ${ }^{25}$, respectively. The EIS structure is biased towards depletion or inversion. An intensity modulated laser beam focused into the semiconductor generates electron-hole pairs, which separate in the depletion layer and cause a local photocurrent to flow through the structure. While LAPS measures local potential changes (e.g. caused by changes in the surface charge of the insulator) by recording the shift of the photocurrent-voltage $(I-V)$ curve along the voltage axis, SPIM records changes in the maximum photocurrent while the EIS structure is biased towards inversion. Both techniques have been extensively applied for chemical ion sensing $26,27,28$, biosensing $29,30,31$, and the investigation of cell metabolism, extracellular potentials, cell surface charge and impedance ${ }^{32}$, 33, 34 . Importantly, they have been reported to be highly sensitive to the surface contamination on self-assembled organic monolayers ${ }^{23}$. In this report, we employed LAPS and SPIM to study the copper(I) residue that remains on alkyne-terminated silicon surfaces following 'click' reactions, as well as the electrochemical properties of the functionalized organic monolayers. Firstly, the silicon on sapphire (SOS) sensor substrates were modified with 1,8nonadiyne self-assembled organic monolayers, serving as the insulator for LAPS and SPIM with high sensitivity ${ }^{23}$. The subsequent $\mathrm{CuAAC}$ 'click' reaction combined with $\mu \mathrm{CP}$ created a pattern with both 'clicked' areas and unreacted alkyne-terminated areas to allow 2D imaging 
of the electrical properties (surface charge and impedance) of 'click' modified surfaces with LAPS and SPIM.

\section{Experimental section}

\subsection{Materials.}

Silicon-on-sapphire (SOS) with a $1 \mu \mathrm{m}$ thick silicon (100) layer (boron doped, $0.1 \Omega \cdot \mathrm{cm}$ ) on a $475 \mu \mathrm{m}$ thick sapphire substrate was purchased from Monocrystal, Russia. Double polished silicon (100) (boron doped, 10-30 $\Omega \cdot \mathrm{cm}, 500 \mu \mathrm{m}$ thickness) was purchased from Si-MAT, Germany. All chemicals and reagents were purchased from Sigma-Aldrich, unless otherwise noted. The following reagents were used as received: hydrogen peroxide solution (30 wt. \% in $\mathrm{H}_{2} \mathrm{O}$, semiconductor grade), sulfuric acid (95.0-98.0\%, semiconductor grade), hydrochloride acid (ACS regent), ethylenediaminetetraacetic acid tetrasodium salt hydrate (EDTA, 98\%), ethanol (100\%), sodium ascorbate (98\%), copper(II) sulfate pentahydrate (99\%), $N, N, N^{\prime}, N^{\prime}$-tetramethylethylenediamine (TMEDA, $\geq 99.5 \%$ ), copper(I) bromide, tetrakis(acetonitrile) copper(I) hexafluorophosphate $\left(\mathrm{Cu}(\mathrm{I})-\mathrm{PF}_{6}, 97 \%\right)$, tris[(1-benzyl-1H1,2,3-triazol-4-yl)methyl] (TBTA, 97\%), 3-azido-1-propanamine (azido- $\mathrm{NH}_{2}$, technical, $\geq 90 \%$ (GC)) and dimethyl sulfoxide (DMSO, $\geq 99.5 \%$ ). Dichloromethane (DCM) was redistilled prior to use for cleaning. 1,8-Nonadiyne (98\%) was redistilled from sodium borohydride $(99+\%)$ and stored under $\operatorname{argon}^{10,35}$. A Sylgard 184 poly(dimethyl siloxane) (PDMS) kit was purchased from Dow Corning. For photocurrent measurements and cyclic voltammetry, $10 \mathrm{mM}$ phosphate buffer solution $\mathrm{pH} 7.4$ containing $137 \mathrm{mM} \mathrm{NaCl}$ and $2.7 \mathrm{mM} \mathrm{KCl}$ was used. All solutions were prepared with ultrapure water $(18.2 \Omega \cdot \mathrm{cm})$ from a three stage Millipore Milli-Q 185 water purification system (Millipore, USA). Argon was dried and purified through an oxygen/moisture trap (Agilent Technologies, USA). 


\subsection{Assembly of 1,8-nonadiyne monolayer.}

Silicon-on-sapphire (SOS) wafers and double polished silicon wafers were cut into $7 \mathrm{~mm} \times 7$ $\mathrm{mm}$ pieces. In order to form an ohmic contact on SOS substrates for photocurrent measurements, $30 \mathrm{~nm} \mathrm{Cr}$ and $150 \mathrm{~nm} \mathrm{Au}$ were thermally evaporated onto one corner of the front-side silicon layer and subsequently heated to $300{ }^{\circ} \mathrm{C}$ for 5 min as previously reported ${ }^{23}$, 24, 36. The substrate was cleaned in a hot piranha solution $\left(3: 1 \mathrm{H}_{2} \mathrm{SO}_{4}(96 \%) / \mathrm{H}_{2} \mathrm{O}_{2}(30 \%)\right.$, caution: highly corrosive) at $100{ }^{\circ} \mathrm{C}$ for $30 \mathrm{~min}$ and then rinsed copiously with ultrapure (Milli-Q) water. The assembly of the 1,8-nonadiyne monolayer followed a procedure reported previously ${ }^{10,23}$. The cleaned SOS or silicon sample was transferred to a $2.5 \% \mathrm{HF}$ solution and chemically etched for $90 \mathrm{~s}$ to obtain an H-terminated surface (caution: HF is highly corrosive). During the cleaning and etching time, the redistilled 1,8-nonadiyne was transferred into a Schlenk tube and was degassed by freeze-pump-thaw cycles until no gas bubbles evolved from the solution. Then the freshly prepared H-SOS or H-Si sample was transferred into the degassed 1,8-nonadiyne and left for $3 \mathrm{~h}$ at $165^{\circ} \mathrm{C}$ under an argon stream. After cooling to room temperature, the functionalized surface (surface 1, Scheme 1a) was then rinsed with copious amounts of redistilled DCM and blown dry with nitrogen. 
(a)

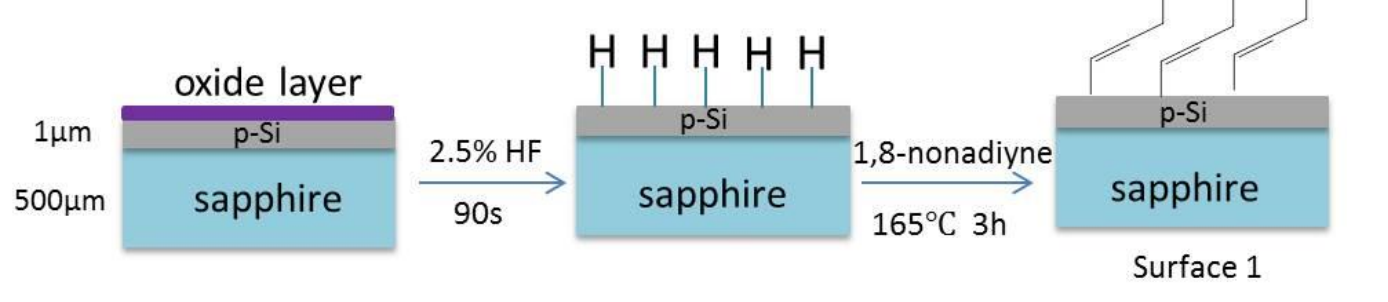

(b)

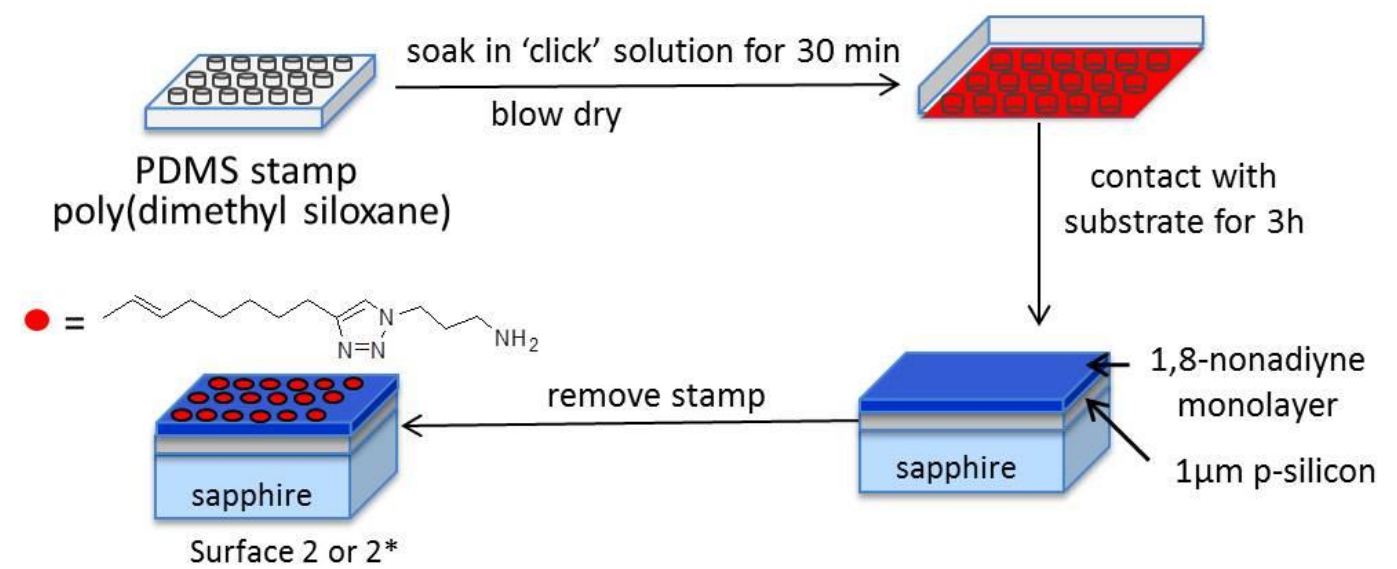

Scheme 1. (a) Surface modification of SOS substrates with 1,8-nonadiyne (surface 1) (b) schematic illustration of the $\mu \mathrm{CP}$ of 'click' chemistry: azido- $\mathrm{NH}_{2}$ was printed on surface 1 and 'click' reactions occurred exclusively in the contact area (surface 2: an array of chemical pattern, surface $2^{*}$ : a homogeneous surface functionalized with azido- $\mathrm{NH}_{2}$ by a flat featureless PDMS stamp). For ellipsometry measurements, the above surface modification was carried out on silicon substrates.

\subsection{Microcontact printing $(\mu \mathrm{CP})$ for 'click' chemistry.}

The master and PDMS stamps were prepared following a previously reported protocol $^{22,24,37}$. The pattern of the PDMS stamp consisted of circular islands with a diameter of $100 \mu \mathrm{m}$ and $40 \mu \mathrm{m}$ gaps. Scheme $1 \mathrm{~b}$ illustrates the process of 'click' chemistry on surface 1 using $\mu \mathrm{CP}$. The PDMS stamps were firstly treated in an oxygen plasma (pressure: 0.8 Torr, generator: 40 $\mathrm{kHz} / 100 \mathrm{~W}$ ) for $30 \mathrm{~s}$ to make the stamp surfaces hydrophilic. Then, they were immersed in 
the 'click' solutions for $30 \mathrm{~min}$. Herein, three alternative 'click' solutions, displayed as solution A, B and C, were employed, consisting of (A) the azido- $\mathrm{NH}_{2}(10 \mathrm{mM}$, ethanol/water 2:1), copper(II) sulfate pentahydrate ( $1.1 \mathrm{~mol} \%$ relative to the azide), sodium ascorbate (10 mol\% relative to the azide) and TMEDA $(0.45 \mathrm{mM}),(\mathrm{B})$ the azido- $\mathrm{NH}_{2}(10 \mathrm{mM}, \mathrm{DMSO})$, $\mathrm{CuBr}$ (10 mol\% relative to the azide) and TMEDA (20 mol \% relative to the azide), $(\mathrm{C})$ the azido- $\mathrm{NH}_{2} \quad(10 \mathrm{mM}, \quad$ DMSO$)$, tetrakis(acetonitrile) copper(I) hexafluorophosphate $\left[\mathrm{Cu}\left(\mathrm{CH}_{3} \mathrm{CN}\right)_{4}\right]\left(\mathrm{PF}_{6}\right)(10 \mathrm{~mol} \%$ relative to the azide $)$ and tris[(1-benzyl-1H-1,2,3-triazol-4yl)methyl] (TBTA) (10 mol\% relative to the azide), respectively. The soaked stamps were dried under nitrogen gas and placed onto the alkyne-terminated surface for $3 \mathrm{~h}$ at room temperature. The reactions were carried out in a sealed Petri dish in the presence of a moistened tissue. After removing the stamps, the unreacted reagents were removed by rinsing the substrate consecutively with copious amounts of DMSO, ethanol, water and ethanol. The resultant corresponding 'click' modified surfaces are referred to as surface $2 a, 2 b$ and $2 c$. Then the samples were rinsed in either a $0.5 \mathrm{M}$ hydrochloric acid solution for $2 \mathrm{~min}$, or EDTA $(0.05 \% \mathrm{w} / \mathrm{v}, \mathrm{pH} 7.4)$ for 24 hours to remove the copper residue and rinsed with copious amounts of water. To characterize the "clicked" surface properly, chemically homogeneous surfaces ( surface $2 \mathrm{a}^{*}, 2 \mathrm{~b}^{*}$, and $2 \mathrm{c}^{*}$ ) were also prepared using a flat featureless PDMS stamp following the same procedure. As control experiments, inks ('click' solutions A, B and C) without azide were printed on surface 1 using the same procedure in Scheme 1b, indicated as control surfaces $a, b$ and $c$.

\subsection{Surface characterization.}

The water contact angle measurements were performed using a Drop Shape Analysis System (Krüss DSA100, Germany). $1 \mu \mathrm{L}$ of ultrapure water was carefully deposited onto sample surface and three spots were measured on each sample and averaged. 
An alpha-SE ${ }^{\circledR}$ Spectroscopic Ellipsometer (J.A. Woollam Co. Inc., USA) and CompleteEASE software (J.A. Woollam Co. Inc., USA) for data collection and analysis were used to measure the thickness of monolayers on silicon surfaces. A He-Ne laser $(632.8 \mathrm{~nm})$ and an angle of incidence of $70^{\circ}$ were adopted.

X-ray photoelectron spectroscopy (XPS) experiments were performed on modified SOS surfaces at the nanoLAB of Newcastle University, UK, using a Kratos Axis Nova spectrometer with CasaXPS software. Samples used for XPS measurements were all prepared with flat, featureless PDMS stamps (see 2.3). Survey scans were carried out over a 1100-0 eV range with a $1.0 \mathrm{eV}$ step size, a $100 \mathrm{~ms}$ dwell time, and an analyzer pass energy of $100 \mathrm{eV}$. High-resolution scans were run with a $0.1 \mathrm{eV}$ step size, a dwell time of $100 \mathrm{~ms}$, and the analyser pass energy set to $20 \mathrm{eV}$. The scan regions were Si 2p (97-107 eV), C 1s (278-294 eV), N 1s (392-408 eV), O 1s (526-542 eV) and $\mathrm{Cu} 2 \mathrm{p}_{3 / 2}(926-938 \mathrm{eV})$.

Cyclic voltammetry was performed in a $10 \mathrm{mM}$ PBS solution $(\mathrm{pH}=7.4)$ described above using an Autolab PGSTAT30/FRA2 (Windsor Scientific Ltd., UK) with a three-electrode system including a platinum electrode as the counter electrode, an $\mathrm{Ag} / \mathrm{AgCl}$ electrode as reference electrode, and a modified SOS substrate as the working electrode. The scan rate was $50 \mathrm{mV} / \mathrm{s}$.

\subsection{LAPS and SPIM setup.}

The experimental setup for photocurrent measurements has been described elsewhere ${ }^{23}$. LAPS measurements were carried out using a focused and electronically modulated diode laser LD1539 (Laser 2000, $\lambda=405 \mathrm{~nm}$, max. $50 \mathrm{~mW}$, focused spot diameter $\sim 1 \mu \mathrm{m}$ ). The modulation frequency was $1 \mathrm{kHz}$ for all photocurrent measurements. For each measurement, three repeats were performed. To obtain a good spatial resolution, the sensor chips used for LAPS measurements were all based on SOS substrates ${ }^{38}$. 


\section{Results and discussion}

\subsection{Assembly of 1,8-nonadiyne and 'click' functionalization by $\mu \mathrm{CP}$.}

1,8-Nonadiyne monolayers were characterized by water contact angle, ellipsometry and XPS. As shown in Table 1, a water contact angle of $86^{\circ}$ which indicated a hydrophobic monolayer, and an ellipsometric thickness of $9.2 \AA$ for an alkyne-terminated surface are comparable to literature results ${ }^{14,23,35}$. XPS spectra of the modified SOS surface (Figure 1a) showed the presence of $\mathrm{Si}, \mathrm{C}$, and $\mathrm{O}$, which is in good agreement with results published previously ${ }^{3,10,35}$. The high-resolution narrow scans of XPS provide information on surface bonding. The C 1s narrow scan included a main C-C peak $(\sim 285 \mathrm{eV})$, and two small peaks from $\mathrm{Si}-\mathrm{C}=\mathrm{C}(\sim 284$ $\mathrm{eV})$ and C-O (286.5 eV) (Figure $1 \mathrm{~b})$. The binding energies observed were consistent with the results reported elsewhere ${ }^{10,35}$. The alkyne-terminated organic monolayers on silicon surfaces provide a platform for further functionalization via CuAAC 'click' chemistry.

Table 1. Contact angles and ellipsometry thicknesses of different surfaces

\begin{tabular}{|c|c|c|c|}
\hline Surface & 'Click' catalyst & Water contact angle & Ellipsometry thickness \\
\hline SOS- & - & $86 \pm 1$ & $9.2 \pm 0.3$ \\
\hline $2 a^{*}$ SOS-NH 2 & $\mathrm{CuSO}_{4} /$ sodium & $56 \pm 2$ & $14.9 \pm 0.5$ \\
\hline $2 b^{*}$ SOS-NH 2 & $\mathrm{CuBr}$ & $55 \pm 2$ & $14.3 \pm 0.6$ \\
\hline $2 \mathrm{c} * \mathrm{SOS}-\mathrm{NH}_{2}$ & {$\left[\mathrm{Cu}\left(\mathrm{CH}_{3} \mathrm{CN}\right)_{4}\right]\left(\mathrm{PF}_{6}\right)$} & $56 \pm 3$ & $15.2 \pm 0.4$ \\
\hline
\end{tabular}



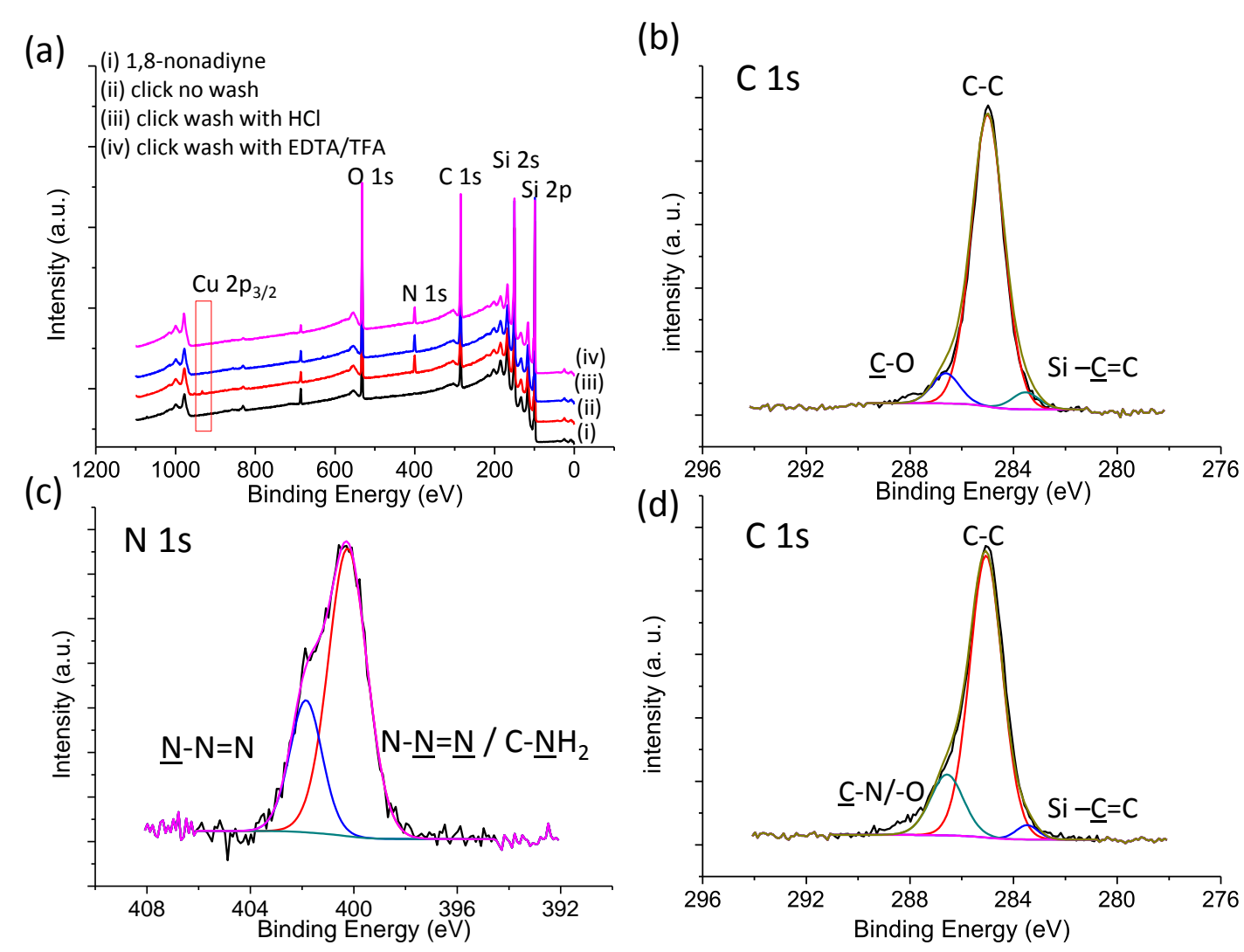

Figure 1. (a) XPS spectrum of samples modified with 1,8-nonadiyne (i), and 3-azido-1propanamine without any further cleaning to remove copper residue (ii), with further cleaning with $0.5 \mathrm{M} \mathrm{HCl}$ for $2 \mathrm{~min}$ (iii) ,and with further cleaning with $0.05 \%$ EDTA/TFA for 24 hours (iv). Narrow scans of (b) C 1s of surface 1, (c) N 1s and (d) C 1s of surface 2a*.

For 'click' conditions A, the water contact angle of the 'clicked' surface (surface 2a*) decreased to $56^{\circ}$ (Table 1) due to the amino moieties, which is in agreement with previously reported values ${ }^{14}$. The ellipsometric result shows that after the 'click' reaction, the thickness of the monolayer increased to $\sim 14.9 \AA$, which is comparable to the thickness of $15.3 \AA$ determined from X-ray reflectivity (XRR) analysis ${ }^{14}$. The successful 'click' reaction was also demonstrated by XPS results. The presence of an N 1s peak at $\sim 401 \mathrm{eV}$ in the XPS survey spectrum (Figure 1a) indicated the formation of a triazole. The narrow scan signal of the $\mathrm{N} 1 \mathrm{~s}$ region (Figure 1c) was deconvoluted and fitted to two peaks at $400.2 \mathrm{eV}$ and $401.8 \mathrm{eV}$, which 
were assigned to $\mathrm{C}-\underline{\mathrm{NH}}_{2} / \mathrm{N}-\underline{\mathrm{N}}=\underline{\mathrm{N}}$, and $\underline{\mathrm{N}}-\mathrm{N}=\mathrm{N}$, respectively. The ratio of the peaks areas is about 2.6:1, which is slightly smaller than the stoichiometric ratio of $3: 1$, but is consistent with literature results ${ }^{14,15}$. The absence of a peak at $403 \mathrm{eV}$, which corresponds to the central electron-deficient nitrogen in the azido groups, showed that there was no physisorption of azide on the silicon surface. The narrow scan from the $\mathrm{C}$ 1s region (Fig 1d) was deconvoluted into three peaks assigned to $\mathrm{Si}-\underline{\mathrm{C}}=\mathrm{C}(284.2 \mathrm{eV}), \mathrm{C}-\mathrm{C}(285.3 \mathrm{eV})$ and $\underline{\mathrm{C}}-\mathrm{N} /-\mathrm{O}(286.8 \mathrm{eV})^{14}$, 15. An increased ratio of $\underline{\mathrm{C}}-\mathrm{N} /-\mathrm{O}$ to $\mathrm{Si}-\underline{\mathrm{C}}=\mathrm{C}$ was due to the successfully bonded amino group on silicon surfaces. After 'click' modification, a copper peak at $\sim 933 \mathrm{eV}$ was only visible when the sample was not rinsed with either $\mathrm{HCl}$ or EDTA solutions (Figure 1a). The narrow scan of $\mathrm{Cu} 2 \mathrm{p} 3 / 2$ could be fitted to only one peak at $933.2 \mathrm{eV}$ which is consistent with copper(I) ${ }^{10}$. No copper peak was visible after rinsing with either reagent. Two alternative strategies for 'click' modification were verified with water contact angle and ellipsometry results (Table 1, entries $2 \mathrm{~b}$ and $2 \mathrm{c}$ ).

\subsection{Copper residue visualized with LAPS and SPIM.}

LAPS and SPIM have been validated to be very sensitive techniques to detect the properties of surface electrical potential and impedance, respectively, with spatial resolution. To ensure that no artefacts were introduced by the $\mu \mathrm{CP}$, a control experiment with a blank PDMS stamp on a 1,8-nonadiyne modified SOS sample was carried out. Neither LAPS nor SPIM images showed any patterns confirming that the PDMS stamp did not leave any residue or damage the monolayer. Figure $2 \mathrm{a}$ shows the SPIM image of surface $2 \mathrm{a}$ after rinsing in $0.5 \mathrm{M} \mathrm{HCl}$ solution for 2 min measured at $0.8 \mathrm{~V}$, which is identical to the pattern on the PDMS stamp used. The time for one scan was about $15 \min$ (area $500 \mu \mathrm{m}$ x $500 \mu \mathrm{m}$, step size $5 \mu \mathrm{m}$ ). At the selected voltage, the photocurrent was greater on the 'click' reaction modified spots than on the blank 1,8-nonadiyne modified area (also see Figure 2b), which was unexpected, as the thickness of the modified spot increased after the 'click' reaction, which should have resulted 
in a reduced capacitance and thus a decreased photocurrent. In addition, there was also a negative shift of $-86 \pm 5 \mathrm{mV}$ on the 'click' reaction modified spots compared to the blank 1,8 nonadiyne modified area in the lower part of the normalized $I$ - $V$ curves (Figures $2 \mathrm{c}$ ), which was much bigger than a previously reported shift of $-50 \mathrm{mV}$ caused by positively charged amino groups ${ }^{23}$. Whilst this is an empirical observation, we speculated that this effect was the result of residual positively charged copper(I) ions remaining associated with the monolayer, which consequently increased its conductivity thereby increasing the local photocurrent and causing the negative shift of the $I-V$ curves. The increase in the maximum photocurrent indicates that copper(I) is not simply adsorbed onto the surface of the monolayer, but that it enters the monolayer. The appearance of a step in the I-V curve after $\mu \mathrm{CP}$ indicates the presence of different surface charges within the illuminated spot on the sample due to incomplete coverage caused by the printing process. This is in agreement with results reported previously for the $\mu \mathrm{CP}$ of polyelectrolytes on monolayer modified SOS surfaces ${ }^{24}$.

(a)

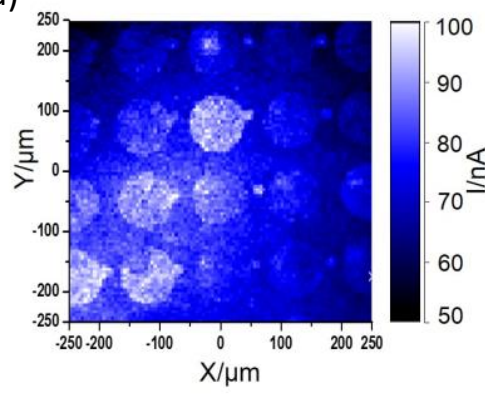

(b)

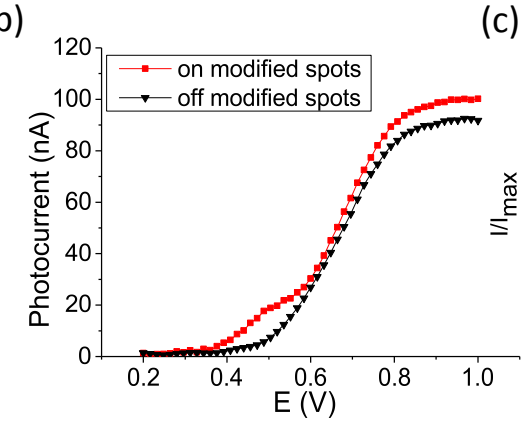

(c)

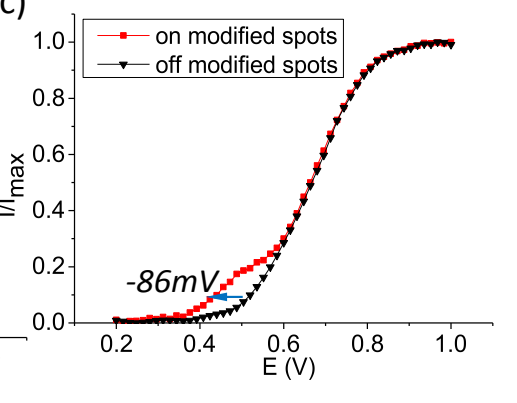

Figure 2. The SPIM image of a 1,8-nonadiyne modified SOS sample patterned with 3 azido1-propanamine with a 'click' reaction (surface 2a) after cleaning with (a) $\mathrm{HCl}$ solution and corresponding (b) $I-V$ curves $\left(I_{\max -o n}=101.3 \pm 2.7 \mathrm{nA}, I_{\max -o f f}=91.7 \pm 0.6 \mathrm{nA}\right)$ and (c) normalized curves.

To verify this, a control surface $a$ was prepared by printing the copper catalyst without azide on the 1,8-nonadiyne modified surface following the procedure set out in Scheme 1b, and 
rinsing with $0.5 \mathrm{M} \mathrm{HCl}$ solution for $2 \mathrm{~min}$. The corresponding SPIM image at a bias voltage of $0.8 \mathrm{~V}$, also showed an increased photocurrent on modified spots compared to the blank 1,8-nonadiyne modified area (Figures $3 \mathrm{a}$ and $\mathrm{b}$ ). The $I$ - $V$ curves shifted by $-23 \pm 2 \mathrm{mV}$ in the lower part, again indicating positive charge on the modified spots (Figure 3c). Thus, the presence of a copper(I) residue on the surface after the 'click' reaction despite cleaning with hydrochloric acid solution was verified using LAPS and SPIM, although there was an absence of $\mathrm{Cu} 2 \mathrm{p}_{3 / 2}$ emission at $\sim 933 \mathrm{eV}$ in the XPS spectra (Figure 1a), demonstrating that LAPS and SPIM are highly sensitive in detecting the presence of copper ions. The copper(I) ion residue was also confirmed by a cyclic voltammogram obtained from the control surface $a$, which showed a peak at $0.24 \mathrm{~V}$, corresponding to the oxidation of copper(I) on the surface $^{39}$, while no peak was observed in the cyclic voltammogram measured on a blank 1,8nonadiyne modified surface (Figure 4). Integration of the oxidation peak yielded a surface concentration of $1.1 \times 10^{-11} \mathrm{~mol} / \mathrm{cm}^{2}$. 
(a)

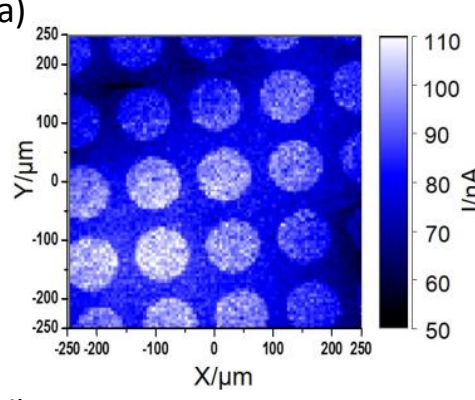

(d)

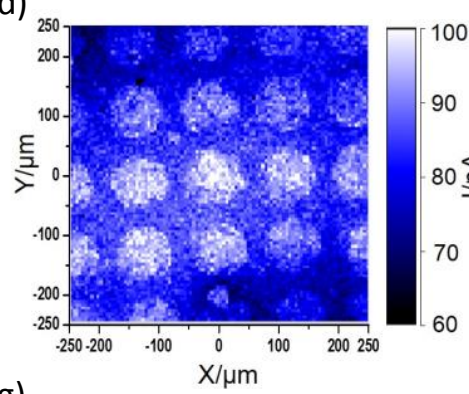

(g)

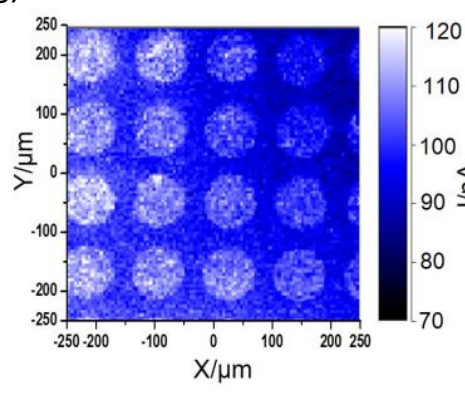

(b)

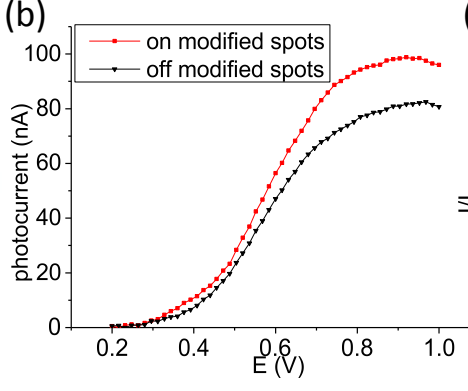

(e)
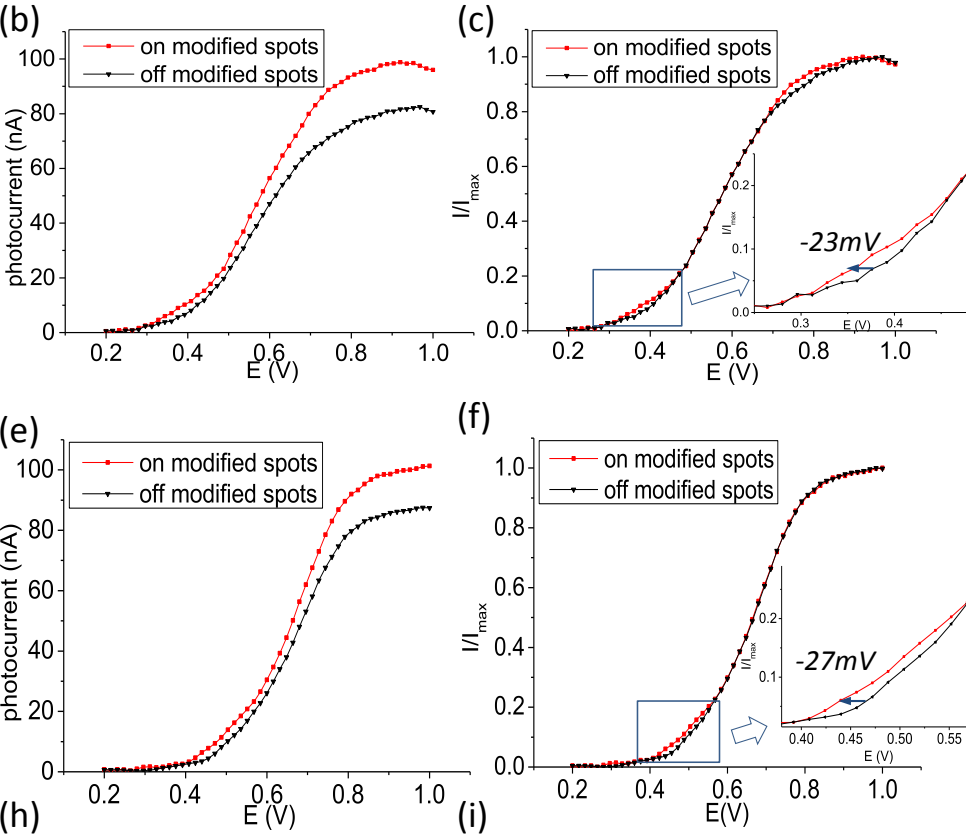

(f)
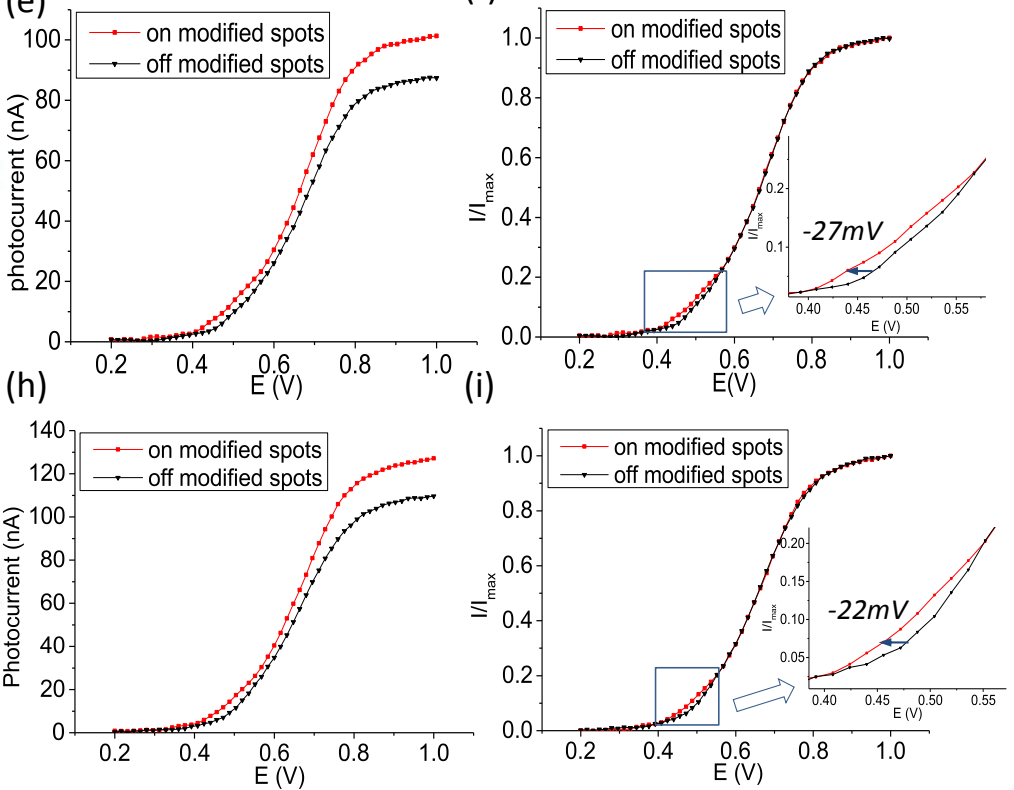

Figure 3. SPIM images at a bias voltage of $0.8 \mathrm{~V}$ on (a) control surface $a$, (d) control surface $b$ and $(\mathrm{g})$ control surface $c$ after rinsing with $0.5 \mathrm{M} \mathrm{HCl}$ for $2 \mathrm{~min}$, and the corresponding $I-V$ curves (b) $\left(I_{\max -o n}=98.1 \pm 1.1 n A, I_{\max -\text { off }}=79.4 \pm 1.6 n A\right),(\mathrm{e})\left(I_{\max -o n}=98.7 \pm 2.6 n A, I_{\text {max-off }}\right.$ $=87.7 \pm 1.0 \mathrm{nA})$, (h) $\left(I_{\max -o n}=124.4 \pm 2.3 n A, I_{\max -o f f}=108.6 \pm 1.3 \mathrm{nA}\right)$ on modified spots (red) and non-modified 1,8-nonadiyne areas (black) and normalized $I$ - $V$ curves (c), (f), (i).

To investigate if a copper(I) residue was also found in 1,8-nonadiyne monolayers for 'click' reactions in organic solvents with subsequent cleaning with $\mathrm{HCl}$ solution, 'click' conditions using $\mathrm{CuBr}$ and TMEDA in DMSO, which have frequently been used to immobilize waterimmiscible molecules via 'click' reactions on alkyne-terminated surfaces ${ }^{4,5,11,15}$, were tested and investigated with LAPS and SPIM. Figure $3 d$ shows the SPIM image of control surface $b$ after rinsing with $\mathrm{HCl}$ solution at a bias voltage of $0.8 \mathrm{~V}$, which also displayed a greater 
photocurrent on modified spots than the unmodified area of 1,8-nonadiyne (also see Figure 3e), indicating a smaller impedance on modified spots and, hence, the presence of trapped copper ions in the monolayer, which enhanced its conductivity. The nature of the entrapment is not known. It is possible that copper(I) ions are chelated by the terminal alkyne group of the monolayer or that they penetrate deeper into the monolayer. The corresponding normalized $I-V$ curves shifted by $-27 \pm 2 \mathrm{mV}$ in the lower part for the modified area (Figure 3f), resulting from the positively charged copper ions, which was also comparable to the shift of $-23 \mathrm{mV}$ obtained from the previous control surface $a$ after rinsing with $\mathrm{HCl}$.

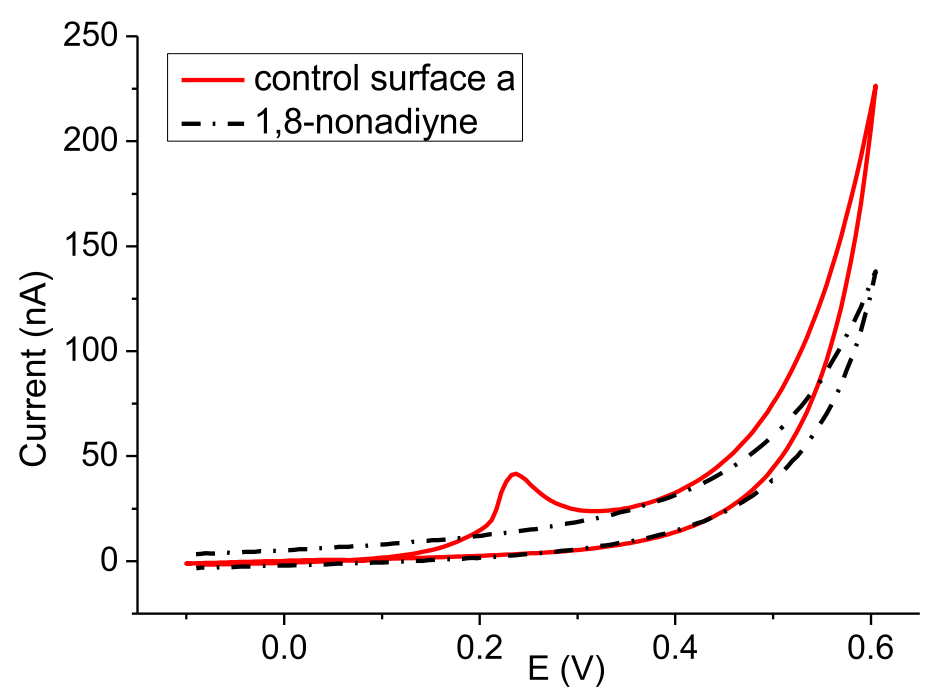

Figure 4. Cyclic voltammograms of control surface $a$ after rinsing with $\mathrm{HCl}$ (red solid line) and a blank 1,8-nonadiyne modified surface (black dashed line) in $10 \mathrm{mM}$ PBS solution (pH 7.4) with a scan rate of $50 \mathrm{mV} / \mathrm{s}$.

\subsection{Strategies for avoiding a copper(I) residue after click modification.}

A residue of copper(I) ions in the monolayer following "click" modification is undesirable because it can interfere with the subsequent function of the device, as clearly demonstrated by the LAPS and SPIM measurements presented above, and because copper ions could 
adversely affect biological systems. Several strategies were investigated to avoid copper contamination of the monolayer. It was hypothesized that if a stable, bulky copper(I) complex with a large counter ion was employed as the catalyst, it might prevent copper from entering the monolayer. Therefore tetrakis(acetonitrile) copper(I) hexafluorophosphate was combined with the bulky ligand tris[(1-benzyl-1H-1,2,3-triazol-4-yl)methyl] (TBTA $)^{40,41,42}$ and the complex used to catalyze the $\mathrm{CuAAC}$ reaction. Again, an increased photocurrent on the "click" modified spots in the SPIM image (Figures $3 \mathrm{~g}$ and $\mathrm{h}$ ) and a shift of $-22 \pm 2 \mathrm{mV}$ in the lower part of the corresponding normalized $I-V$ curves (Figure 3i) with respect to the 1,8 nonadiyne modified area on control surface $c$ were observed, revealing the existence of a copper residue in the monolayer. From the above experiments, it was apparent that rinsing the samples with $\mathrm{HCl}$ after "click" modification was insufficient to remove the copper(I) residue completely, irrespective of the type of copper catalyst or the solvent used for 'click' modification.

Another common method used for removing copper after a 'click' reaction has been rinsing the surface with a $0.05 \% \mathrm{w} / \mathrm{v}$ EDTA solution $(\mathrm{pH}=7.4)$ for 24 hours $^{35,43,44}$. It is noteworthy that both $\mathrm{HCl}$ and trifluoroacetic acid (TFA) were used to adjust the $\mathrm{pH}$ of the tetrasodium salt of EDTA solution to be 7.4 in our study, abbreviated as EDTA/HCl and EDTA/TFA solutions below. Figure 5a shows the LAPS image of control surface $a$ following rinsing with EDTA/HCl at a bias voltage of $0.5 \mathrm{~V}$. The corresponding $I-V$ curves displayed no maximum photocurrent difference (Figure 5b), but again a small voltage shift of $-10 \pm 1 \mathrm{mV}$ in the lower part between modified spots and the blank 1,8-nonadiyne modified area (Figure 5c) indicates that whilst more copper has been removed compared to the cleaning method with aqueous $\mathrm{HCl}$ solution, there is still residual copper in the monolayer. This result also reveals that the photocurrent measurements are more sensitive in detecting surface charges than impedance. The LAPS and SPIM results observed after rinsing the control surface with an 
EDTA solution obtained by adjusting the $\mathrm{pH}$ of a solution of the disodium salt of EDTA to 7.4 with sodium hydroxide were similar to those after rinsing with EDTA/HCl.

In contrast, no pattern was observed in the SPIM image at $0.8 \mathrm{~V}$ (Figure 5d) and the LAPS image at $0.5 \mathrm{~V}$ (Figure 5e) of the control surface after rinsing in EDTA/TFA solution for 24 hours. Thus, rinsing samples after a 'click' reaction with an EDTA/TFA solution is clearly more effective in removing copper residues than an EDTA/HCl solution or an EDTA solution without $\mathrm{HCl}$. We assume that the presence of trifluoroacetate ions in the EDTA solution is required to remove copper ions from the film, possibly going through the intermediate of a copper(I) trifluoroacetate alkyne complex ${ }^{45}$.

(a)

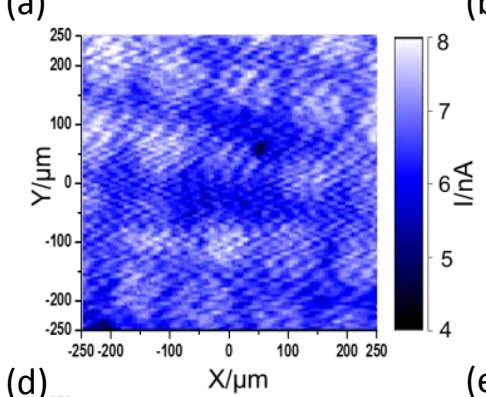

(d)

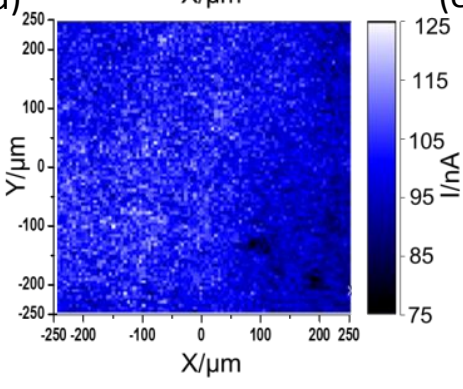

(b)
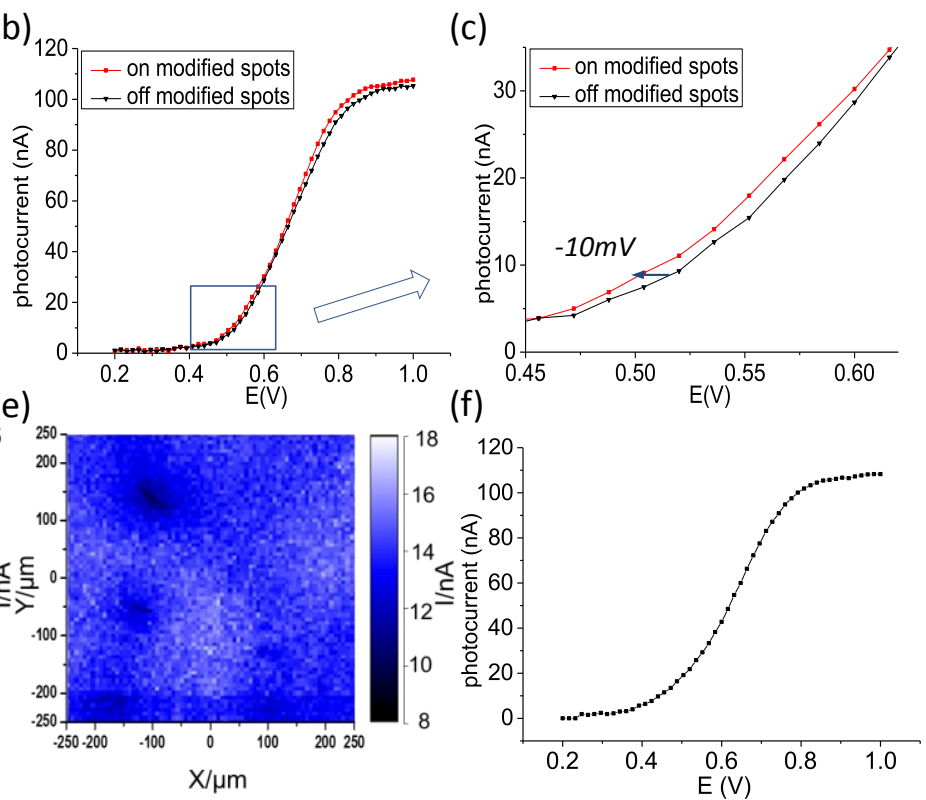

Figure 5. (a) LAPS image of control surface a rinsing with EDTA/HCl for 24 hours at a bias voltage of $0.5 \mathrm{~V}$, (b) the corresponding $I$ - $V$ curves on modified spots and blank 1,8-nonadiyne modified area $\left(I_{\max -o n}=104.5 \pm 1.4 n A, I_{\max -o f f}=105.0 \pm 3.6 n A\right)$, and (c) enlarged $I-V$ curves with a voltage shift of $-10 \mathrm{mV}$. (d) SPIM image and (e) LAPS image of control surface a rinsing with EDTA/TFA for 24 hours at bias voltages of $0.8 \mathrm{~V}$ and $0.5 \mathrm{~V}$, respectively, and (f) corresponding $I-V$ curve. 


\subsection{SPIM and LAPS measurements of a click modified sample after removal of the copper residue.}

Figure 6a shows a SPIM image of surface 2a after rinsing in EDTA/TFA solution for 24 hours at a bias voltage of $0.8 \mathrm{~V}$. A dark pattern was obtained, i.e. on the 'click' modified spots, the photocurrent was smaller than on the blank 1,8-nonadiyne modified area, indicating an increased impedance, as expected. The corresponding $I-V$ curves measured on 'click' modified spots and off the 'click' modified area (1,8-nonadiyne modified background) are shown in Figure $6 \mathrm{~b}$. A decrease of $\sim 10 \%$ of the maximum photocurrent was obtained in the 'click' modified area, corresponding to a capacitance of $0.86 \pm 0.06 \mu \mathrm{F} / \mathrm{cm}^{2}$ calculated using an equivalent circuit model and simplified equation described previously ${ }^{36}$. This is around 1.6 times smaller than the capacitance of the organic monolayer of 1,8-nonadiyne alone (1.44 $\mu \mathrm{F} / \mathrm{cm}^{2}$ ), which is in agreement with the thickness ratio of the 1,8 -nonadiyne monolayer to the 'click' modified monolayer measured by ellipsometry. There was a negative shift of $-65 \pm$ $5 \mathrm{mV}$ on the 'click' modified spots compared to the 1,8-nonadiyne modified area (Figure 6c), which equals the shift difference between the sample with 'click' reaction after cleaning with $\mathrm{HCl}$ solution and the corresponding control sample, demonstrating the successful removal of the copper residue. The potential shift $(-65 \mathrm{mV})$ for this $\mathrm{NH}_{2}$-terminated surface was greater than previously reported values $(-50 \mathrm{mV})$ for surfaces modified with a longer amino group terminated monolayer of 11-azido-3,6,9-trioxaundecan-1-amine. The hydrophilic nature of the 11-azido-3,6,9-trioxaundecan-1-amine may have allowed electrolyte to enter the monolayer and partially screened the positive charge of the amino groups in contrast to the more hydrophobic 3-azido-1-propanamine used in this work ${ }^{46}$. 
(a)

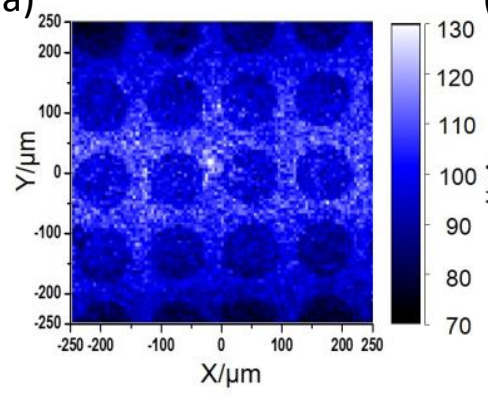

(b)

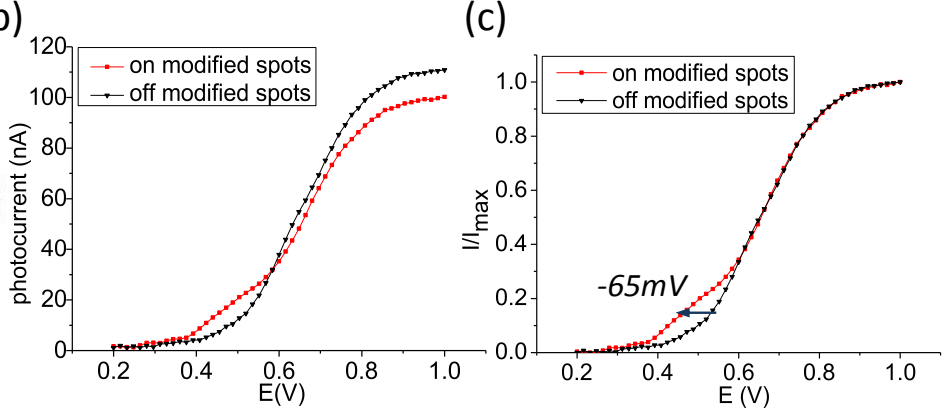

Figure 6. (a) The SPIM image of a 1,8-nonadiyne modified SOS sample patterned with 3 azido-1-propanamine with a 'click' reaction (surface 2a) after cleaning with EDTA/TFA solutions, and corresponding (b) $I$ - $V$ curves $\left(I_{\text {max }-o n}=100.2 \pm 0.1 n A, I_{\text {max }- \text { off }}=112.9 \pm 2.1 \mathrm{nA}\right)$ and (c) normalized curves.

\section{Conclusions}

In this study, we have shown that $\mathrm{HCl}$ is not effective in removing the copper residue after 'click' reactions on alkyne-terminated self-assembled organic monolayers on silicon surfaces, which, although not detectable by XPS, was characterized successfully by LAPS and SPIM. A voltage shift of $-23 \mathrm{mV}$ in the depletion region and the increased maximum photocurrent in the inversion region of the photocurrent curves for the control sample, where only the copper(I) catalyst without azide was printed onto the sample, indicated a positively charged surface and a decreased impedance resulting from copper(I) ions in the monolayer. The presence of the copper(I) residue was also confirmed by the oxidation peak in the cyclic voltammogram on the control sample. The copper residue was completely removed by rinsing samples in a tetrasodium salt of EDTA solution, the $\mathrm{pH}$ of which was adjusted to 7.4 with TFA, after the 'click' reaction. The success of the 'click' reaction was confirmed using LAPS and SPIM. The surface charge properties of the amino group introduced via 'click' reactions by $\mu \mathrm{CP}$ was shown by a voltage shift of $-65 \mathrm{mV}$ in the depletion region of the photocurrent curves. The impedance of the 'clicked' monolayers was detected using SPIM. It 
is envisaged that the high sensitivity of LAPS and SPIM to surface charges and impedance demonstrated in this study makes them promising techniques to measure the electrical properties of biomolecules on surfaces.

Acknowledgements. The authors are grateful to the China Scholarship Council for funding (FW and JW), EU for the providing a Marie Skłodowska-Curie Individual Fellowship (H2020-MSCA-IF-2014-660489) and NEXUS (UK) for XPS measurements.

\section{References}

1. Rohde, R. D.; Agnew, H. D.; Yeo, W.-S.; Bailey, R. C.; Heath, J. R. A non-oxidative approach toward chemically and electrochemically functionalizing $\operatorname{Si}(111)$. J. Am. Chem. Soc. 2006, 128 (29), 9518-9525.

2. Samanta, D.; Sarkar, A. Immobilization of bio-macromolecules on self-assembled monolayers: methods and sensor applications. Chem. Soc. Rev. 2011, 40 (5), 2567-2592.

3. Ciampi, S.; James, M.; Michaels, P.; Gooding, J. J. Tandem "Click" Reactions at Acetylene-Terminated Si(100) Monolayers. Langmuir 2011, 27 (11), 6940-6949.

4. Michaels, P.; Alam, M. T.; Ciampi, S.; Rouesnel, W.; Parker, S. G.; Choudhury, M. H.; Gooding, J. J. A robust DNA interface on a silicon electrode. Chem. Commun. 2014, 50 (58), 7878-7880.

5. Yang, Y.; Ciampi, S.; Choudhury, M. H.; Gooding, J. J. Light Activated Electrochemistry: Light Intensity and $\mathrm{pH}$ Dependence on Electrochemical Performance of Anthraquinone Derivatized Silicon. J. Phys. Chem. C 2016, 120 (5), 2874-2882. 
6. Brooks, K.; Yatvin, J.; McNitt, C. D.; Reese, R. A.; Jung, C.; Popik, V. V.; Locklin, J. Multifunctional Surface Manipulation Using Orthogonal Click Chemistry. Langmuir 2016, $32(26), 6600-6605$.

7. Kolb, H. C.; Finn, M. G.; Sharpless, K. B. Click chemistry: Diverse chemical function from a few good reactions. Angew. Chem.-Int. Edit. 2001, 40 (11), 2004-+.

8. Balaur, E.; Djenizian, T.; Boukherroub, R.; Chazalviel, J. N.; Ozanam, F.; Schmuki, P. Electron beam-induced modification of organic monolayers on $\mathrm{Si}(111)$ surfaces used for selective electrodeposition. Electrochemistry Communications 2004, 6 (2), 153-157.

9. Abel, G. R., Jr.; Cao, B. H.; Hein, J. E.; Ye, T. Covalent, sequence-specific attachment of long DNA molecules to a surface using DNA-templated click chemistry. Chemical Communications 2014, 50 (60), 8131-8133.

10. Ciampi, S.; Bocking, T.; Kilian, K. A.; James, M.; Harper, J. B.; Gooding, J. J. Functionalization of acetylene-terminated monolayers on $\mathrm{Si}(100)$ surfaces: A click chemistry approach. Langmuir 2007, 23 (18), 9320-9329.

11. Choudhury, M. H.; Ciampi, S.; Yang, Y.; Tavallaie, R.; Zhu, Y.; Zarei, L.; Goncales, V. R.; Gooding, J. J. Connecting electrodes with light: one wire, many electrodes. Chem. Sci. 2015, 6 (12), 6769-6776.

12. Zhu, Y.; Soeriyadi, A. H.; Parker, S. G.; Reece, P. J.; Gooding, J. J. Chemical patterning on preformed porous silicon photonic crystals: towards multiplex detection of protease activity at precise positions. J. Mat. Chem. B 2014, 2 (23), 3582-3588.

13. Zhu, Y.; Gupta, B.; Guan, B.; Ciampi, S.; Reece, P. J.; Gooding, J. J. Photolithographic Strategy for Patterning Preformed, Chemically Modified, Porous Silicon 
Photonic Crystal Using Click Chemistry. ACS Appl. Mater. Interfaces 2013, 5 (14), 65146521.

14. James, M.; Ciampi, S.; Darwish, T. A.; Hanley, T. L.; Sylvester, S. O.; Gooding, J. J. Nanoscale Water Condensation on Click-Functionalized Self-Assembled Monolayers. Langmuir 2011, 27 (17), 10753-10762.

15. Ciampi, S.; James, M.; Choudhury, M. H.; Darwish, N. A.; Gooding, J. J. The detailed characterization of electrochemically switchable molecular assemblies on silicon electrodes. Physical Chemistry Chemical Physics 2013, 15 (24), 9879-9890.

16. Hahn, M. S.; Taite, L. J.; Moon, J. J.; Rowland, M. C.; Ruffino, K. A.; West, J. L. Photolithographic patterning of polyethylene glycol hydrogels. Biomaterials 2006, 27 (12), 2519-2524.

17. Rozkiewicz, D. I.; Gierlich, J.; Burley, G. A.; Gutsmiedl, K.; Carell, T.; Ravoo, B. J.; Reinhoudt, D. N. Transfer printing of DNA by "Click" chemistry. Chembiochem 2007, 8 (16), $1997-2002$.

18. Lange, S. A.; Benes, V.; Kern, D. P.; Horber, J. K. H.; Bernard, A. Microcontact printing of DNA molecules. Analytical Chemistry 2004, 76 (6), 1641-1647.

19. Csucs, G.; Michel, R.; Lussi, J. W.; Textor, M.; Danuser, G. Microcontact printing of novel co-polymers in combination with proteins for cell-biological applications. Biomaterials 2003, 24 (10), 1713-1720.

20. Yan, L.; Huck, W. T. S.; Zhao, X. M.; Whitesides, G. M. Patterning thin films of poly(ethylene imine) on a reactive SAM using microcontact printing. Langmuir 1999, 15 (4), 1208-1214. 
21. Mrksich, M.; Whitesides, G. M. PATTERNING SELF-ASSEMBLED MONOLAYERS USING MICROCONTACT PRINTING - A NEW TECHNOLOGY FOR BIOSENSORS. Trends In Biotechnology 1995, 13 (6), 228-235.

22. Hsu, S. H.; Reinhoudt, D. N.; Huskens, J.; Velders, A. H. Imidazolide monolayers for reactive microcontact printing. Journal Of Materials Chemistry 2008, 18 (41), 4959-4963.

23. Wang, J.; Wu, F.; Watkinson, M.; Zhu, J. Y.; Krause, S. "Click" Patterning of SelfAssembled Monolayers on Hydrogen-Terminated Silicon Surfaces and Their Characterization Using Light-Addressable Potentiometric Sensors. Langmuir 2015, 31 (35), 9646-9654.

24. Wang, J.; Zhou, Y. L.; Watkinson, M.; Gautrot, J.; Krause, S. High-sensitivity lightaddressable potentiometric sensors using silicon on sapphire functionalized with selfassembled organic monolayers. Sens. Actuator B-Chem. 2015, 209, 230-236.

25. Krause, S.; Moritz, W.; Talabani, H.; Xu, M.; Sabot, A.; Ensell, G. Scanning PhotoInduced Impedance Microscopy - Resolution studies and polymer characterization. Electrochim. Acta 2006, 51 (8-9), 1423-1430.

26. Yoshinobu, T.; Iwasaki, H.; Ui, Y.; Furuichi, K.; Ermolenko, Y.; Mourzina, Y.; Wagner, T.; Nather, N.; Schoning, M. J. The light-addressable potentiometric sensor for multi-ion sensing and imaging. Methods 2005, 37 (1), 94-102.

27. Ismail, A. M.; Furuichi, K.; Yoshinobu, T.; Iwasaki, H. Light-addressable potentiometric fluoride (F-) sensor. Sens. Actuator B-Chem. 2002, 86 (1), 94-97. 
28. Mourzina, Y. G.; Ermolenko, Y. E.; Yoshinobu, T.; Vlasov, Y.; Iwasaki, H.; Schoning, M. J. Anion-selective light-addressable potentiometric sensors (LAPS) for the determination of nitrate and sulphate ions. Sens. Actuator B-Chem. 2003, 91 (1-3), 32-38.

29. Owicki, J. C.; Bousse, L. J.; Hafeman, D. G.; Kirk, G. L.; Olson, J. D.; Wada, H. G.; Parce, J. W. The Light-Addressable Potentiometric Sensor - Principles and Biological Applications. Annual Review of Biophysics and Biomolecular Structure 1994, 23, 87-113.

30. Poghossian, A.; Yoshinobu, T.; Simonis, A.; Ecken, H.; Luth, H.; Schoning, M. J. Penicillin detection by means of field-effect based sensors: EnFET, capacitive EIS sensor or LAPS? Sens. Actuator B-Chem. 2001, 78 (1-3), 237-242.

31. Wu, C. S.; Poghossian, A.; Bronder, T. S.; Schoning, M. J. Sensing of doublestranded DNA molecules by their intrinsic molecular charge using the light-addressable potentiometric sensor. Sens. Actuator B-Chem. 2016, 229, 506-512.

32. Xu, G. X.; Ye, X. S.; Qin, L. F.; Xu, Y.; Li, Y.; Li, R.; Wang, P. Cell-based biosensors based on light-addressable potentiometric sensors for single cell monitoring. Biosens. Bioelectron. 2005, 20 (9), 1757-1763.

33. Zhang, D.-W.; Wu, F.; Wang, J.; Watkinson, M.; Krause, S. Image detection of yeast Saccharomyces cerevisiae by light-addressable potentiometric sensors (LAPS). Electrochemistry Communications 2016, 72, 41-45.

34. Dantism, S.; Takenaga, S.; Wagner, P.; Wagner, T.; Schoning, M. J. Determination of the extracellular acidification of Escherichia coli K12 with a multi-chamber-based LAPS system. Physica Status Solidi a-Applications And Materials Science 2016, 213 (6), 14791485. 
35. Ciampi, S.; Eggers, P. K.; Le Saux, G.; James, M.; Harper, J. B.; Gooding, J. J. Silicon (100) Electrodes Resistant to Oxidation in Aqueous Solutions: An Unexpected Benefit of Surface Acetylene Moieties. Langmuir 2009, 25 (4), 2530-2539.

36. Wang, J.; Campos, I.; Wu, F.; Zhu, J. Y.; Sukhorukov, G. B.; Palma, M.; Watkinson, M.; Krause, S. The effect of gold nanoparticles on the impedance of microcapsules visualized by scanning photo-induced impedance microscopy. Electrochim. Acta 2016, 208, 39-46.

37. Mehlich, J.; Ravoo, B. J. Click chemistry by microcontact printing on self-assembled monolayers: A structure-reactivity study by fluorescence microscopy. Organic \& Biomolecular Chemistry 2011, 9 (11), 4108-4115.

38. Chen, L.; Zhou, Y.; Jiang, S.; Kunze, J.; Schmuki, P.; Krause, S. High resolution LAPS and SPIM. Electrochemistry Communications 2010, 12 (6), 758-760.

39. De Leener, G.; Evoung-Evoung, F.; Lascaux, A.; Mertens, J.; Porras-Gutierrez, A. G.; Le Poul, N.; Lagrost, C.; Over, D.; Leroux, Y. R.; Reniers, F.; Hapiot, P.; Le Mest, Y.; Jabin, I.; Reinaud, O. Immobilization of Monolayers Incorporating Cu Funnel Complexes onto Gold Electrodes. Application to the Selective Electrochemical Recognition of Primary Alkylamines in Water. J Am Chem Soc 2016.

40. Chan, T. R.; Hilgraf, R.; Sharpless, K. B.; Fokin, V. V. Polytriazoles as copper(I)stabilizing ligands in catalysis. Organic Letters 2004, 6 (17), 2853-2855.

41. Welser, K.; Perera, M. D. A.; Aylott, J. W.; Chan, W. C. A facile method to clickable sensing polymeric nanoparticles. Chemical Communications 2009, (43), 6601-6603. 
42. Berg, R.; Straub, B. F. Advancements in the mechanistic understanding of the coppercatalyzed azide-alkyne cycloaddition. Beilstein Journal Of Organic Chemistry 2013, 9, 27152750.

43. Shamsi, F.; Coster, H.; Jolliffe, K. A. Characterization of peptide immobilization on an acetylene terminated surface via click chemistry. Surface Science 2011, 605 (19-20), $1763-1770$.

44. Ciampi, S.; Le Saux, G.; Harper, J. B.; Gooding, J. J. Optimization of click chemistry of ferrocene derivatives on acetylene-functionalized silicon(100) surfaces. Electroanalysis 2008, 20 (14), 1513-1519.

45. Reger, D. L.; Huff, M. F. Synthesis and Characterisation of copper(I) trifluoroacetate alkyne complexes of the type $\mathrm{Cu}_{4}\left(\mathrm{~m}-\mathrm{O}_{2} \mathrm{CCF}_{3}\right)_{4}(\mathrm{~m} \text {-alkyne })_{2}$ and $\mathrm{Cu}_{2}(\mathrm{~m} \text {-alkyne })_{2}$ and $\mathrm{Cu}_{2}(\mathrm{~m}-$ $\left.\mathrm{O}_{2} \mathrm{CCF}_{3}\right)_{2}(\text { alkyne })_{2}$. Organometallics 1990, 9 (10), 2807-2810.

46. Poghossian, A.; Ingebrandt, S.; Abouzar, M. H.; Schoning, M. J. Label-free detection of charged macromolecules by using a field-effect-based sensor platform: Experiments and possible mechanisms of signal generation. Appl. Phys. A-Mater. Sci. Process. 2007, 87 (3), $517-524$ 
TOC picture:
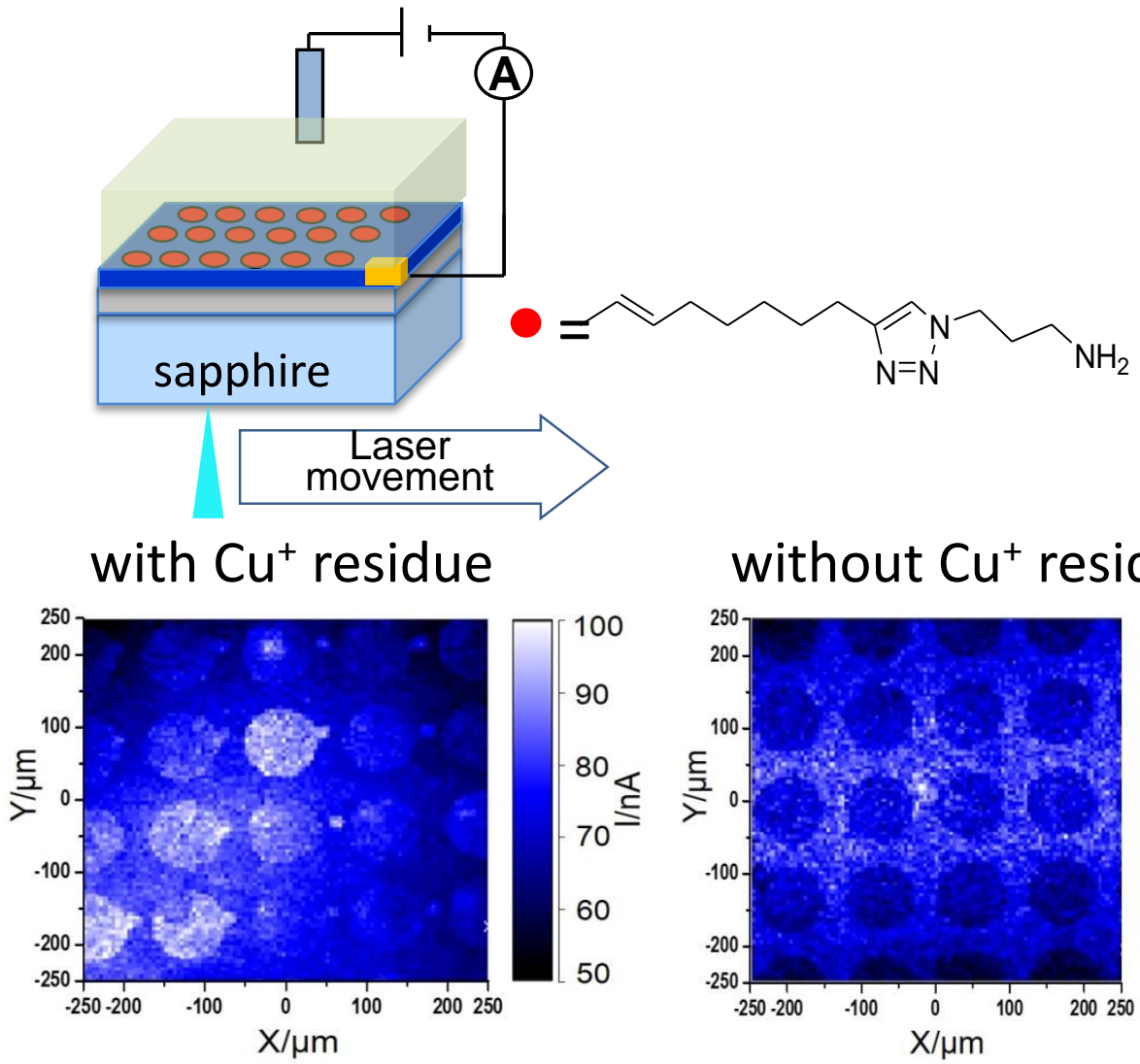

\section{without $\mathrm{Cu}^{+}$residue}

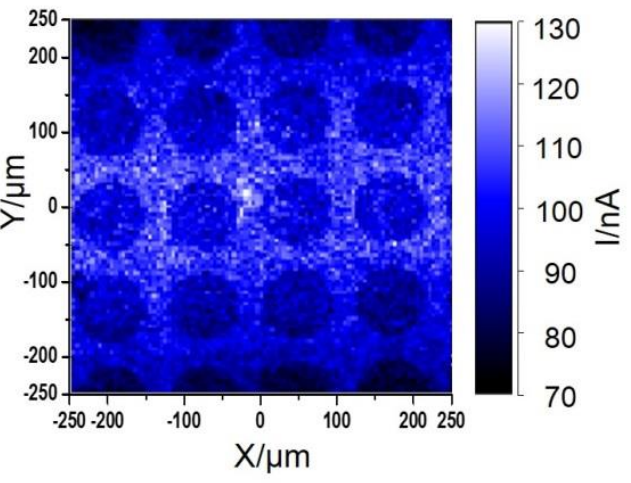

